\title{
Cellular Lipid and the Antistaphylococcal Activity of Phenols
}

\author{
By W. B. HUGO AND IRENE FRANKLIN \\ Department of Pharmacy, The University, Nottingham
}

(Accepted for publication 25 January I968)

\begin{abstract}
SUMMARY
Staphylococcus aureus (OXFORD) when grown in the presence of glycerol increased its cellular lipid content to the extent of $18 \%$ calculated on a cell dry-weight basis. When challenged by a homologous series of 4 - $n$-alkyl phenols $\left(\mathrm{H}-\right.$ to $\left.\mathrm{C}_{6} \mathrm{H}_{13}^{-}\right)$an increase in resistance was noted with the glycerol grown (fattened) cocci after the $4-n$-butyl $\left(\mathrm{C}_{4} \mathrm{H}_{9}-\right)$ phenol. This phenomenon was investigated by means of electrophoresis of single cocci, the measurement of drug uptake, and the effect on leakage of cytoplasmic constituents as well as by the assessment of minimum inhibitory concentrations. Electron micrographs of thin sections of normal and fattened cocci were also examined.
\end{abstract}

\section{INTRODUCTION}

Hugo \& Stretton (1966a,b) showed that when the lipid content of certain Grampositive organisms was increased by growth in the presence of glycerol, these fattened organisms became more resistant to the penicillins, quinacillin, benzylpenicillin, methicillin and cloxacillin; in some cases, when normal lipid content of the organisms was decreased by treatment with lipase, the resistance decreased. It was decided to investigate this phenomenon further but to challenge both fattened and normal organisms with a homologous series of compounds, the 4-alkyl phenols, because the physical properties of this series might be expected to vary in a regular and determinable or determined pattern. Previous findings had shown that the lipid content of the Oxford staphylococcus could be increased threefold on growth in the presence of glycerol; accordingly, this organism was used. Some of the results reported here were briefly reported elsewhere (Hugo \& Franklin, 1966).

\section{METHODS}

Organism. The organism used throughout this work was Staphylococcus aureus, strain OXFORD.

Materials. 4-Methylphenol ( $p$-cresol) and oleyl alcohol were of laboratory reagent grade (British Drug Houses Ltd.); $p$ - $n$-butylphenol and $p$-n-pentyl (amyl) phenol were gifts from Boots Pure Drug Co. Ltd., Nottingham; the remaining phenols were from Kodak Ltd., Kirby, Liverpool. All other chemicals were of analytical reagent quality.

The phenols were purified by distillation, yielding white crystalline products and were stored in sealed amber glass ampoules, from which samples were removed as required. Melting points (uncorrected) of the products so purified were: phenol $43^{\circ}$, 4-methylphenol ( $p$-cresol) $34^{\circ}$, 4-ethylphenol 47-48 , 4- $n$-propylphenol $2 \mathrm{I}-22^{\circ}, 4-n$ butylphenol $22^{\circ}$, 4-sec.-butylphenol $59^{\circ}, 4-n$-pentylphenol (amylphenol) 87-89 $9^{\circ}$, 4 -tert.amylphenol $92-93^{\circ}, 4-n$-hexylphenol $23^{-2} 4^{\circ}$. 
Media and conditions of growth. Culture media were prepared from Oxoid material and contained (g./1.): peptone (Oxoid no. I) Io, meat extract (Lemco, Oxoid) 5, sodium chloride 5, and, where appropriate, glycerol 30. Sterilization was done at I $15^{\circ}$ for 30 min.; final $\mathrm{pH} 7 \cdot 4$.

Buffer solutions. Phosphate buffer was prepared by mixing appropriate quantities of $\mathrm{Na}_{2} \mathrm{HPO}_{4} 12 \mathrm{H}_{2} \mathrm{O}$ and $\mathrm{KH}_{2} \mathrm{PO}_{4} 2 \mathrm{H}_{2} \mathrm{O}$, giving a range from $\mathrm{pH} 5.4$ to $8 \cdot 0$. Tris buffer was used when cellular inorganic phosphate was being investigated. Carbonate + bicarbonate buffer was used in one experiment for the range $\mathrm{pH} 8-10 \cdot 6$.

Determination of minimum inhibitory concentrations. A tube dilution method was used with inoculum to give finally $10^{6} \mathrm{cocci} / \mathrm{ml}$. Results were read after 3 days.

Total lipid and electrophoretic mobilities of cocci. These were determined as previously described (Hugo \& Stretton, 1966a).

Analytical determination of phenols. This was by the colorimetric method of Lykken, Treseder \& Zahn (1946), which involves the conversion of the phenols to nitrosophenols and the determination of the coloured nitrosophenol spectroscopically with a Unicam SP 600 (Cambridge Instruments Ltd.). For each phenol, a calibration curve was constructed from which the phenol content of unknown solutions was calculated. When phenols were to be determined in aqueous solution uncontaminated by cellular constituents the appropriate $\mathrm{D}$ value $\left(\ln I_{0} I\right.$ ) was determined in the ultraviolet region at the previously determined $\lambda_{\max }$ using the SP 500 spectrophotometer (Cambridge Instruments Ltd.). The $\lambda_{\max }$ values lay between 270 and $280 \mathrm{~m} \mu$.

Water solubility of phenols. Water was saturated with the appropriate phenol which was determined spectroscopically. From the optical density of the saturated solution and a solution of known concentration at the appropriate $\lambda_{\max }$ the water solubilities were calculated. Values obtained (g./I00 ml.) were: phenol, 9.37; 4-methylphenol, 2.54; 4-ethylphenol, 0.72; 4-propylphenol $0.36 ; 4$ - $n$-butylphenol, 0.10 ; 4-n-pentylphenol, $0.044 ; 4$ - $n$-hexylphenol. $0.045 ; 4$-sec.-butylphenol, 0.12 , 4-tert.amylphenol, 0.033 .

Distribution coefficients. These were obtained as between oleyl alcohol and 0.067 Mphosphate buffer by adding known volumes of the alcohol and the phenol in the buffer and rotating in a stoppered tube at room temperature until equilibrium was established. A sample of the aqueous layer was assayed for its phenol content spectrophotometrically and the partition coefficient calculated from the following expression:

$\underset{\text { coefficient }}{\operatorname{distribution}}=\frac{\text { Volume of aqueous phase } \times \text { final concentration in oily phase }}{\text { Volume of oily phase } \times \text { final concentration in the aqueous phase }}$

The phosphate buffer held the $\mathrm{pH}$ value at $7 \cdot 4$ but was of a sufficiently high dilution to ensure that the ions did not contribute significantly to the distribution. Phenol concentrations in the initial aqueous layer were of the same order as encountered in the antibacterial studies. Because of the high solubility of the higher members in the oily phase, their concentration in the aqueous phase was too low for reproducible results to be obtained.

Determination of uptake of phenols by Staphylococcus aureus. To $18 \mathrm{ml}$. of the phenol solution was added $2 \mathrm{ml}$. of the bacterial suspension (equiv. Io $\mathrm{mg}$. dry wt $/ \mathrm{ml}$.) in $0.067 \mathrm{M}$-tris buffer $(\mathrm{pH} \mathrm{7.4})$. The mixtures were maintained in a water bath at $37^{\circ}$ and at appropriate times the bacteria were removed by centrifugation twice (I $5 \mathrm{~min}$. each) at $9000 \mathrm{~g}$ and the residual phenol determined by the colorimetric method. 
Determination of phenol-induced leakage of cellular constituents. Determination of leakage of cellular material absorbing at $260 \mathrm{~m} \mu$ is complicated by the $270-280 \mathrm{~m} \mu$ absorbing peak of the phenols. However, by extraction of the supernatant liquid remaining after centrifugation of phenol-treated cocci with three $25 \mathrm{ml}$. amounts of chloroform, the phenols (except phenol itself) were removed and the aqueous layer after warming to remove dissolved chloroform was examined for material absorbing at $260 \mathrm{~m} \mu$. The adequacy of this procedure was tested by mixing the supernatant fluid from boiled cocci, of which the $260 \mathrm{~m} \mu$ absorbing material had been determined, with a solution of each of the phenols in turn, subjecting this mixture to the extraction procedure and redetermining the $260 \mathrm{~m} \mu$ absorbing material; almost quantitative recoveries were obtained. Leakage of cytoplasmic constituents was also investigated by determining inorganic phosphate in the cell-free supernatant fluid by the method of Fiske \& SubbaRow (1925). Phenols, at the concentrations used, did not interfere in this determination.

Preparation of thin sections of cocci and electron microscopy. This was done according to the method described by Hamilton \& Stubbs (1967), with the glutaraldehyde $+\mathrm{OsO}_{4}$ fixative.

\section{RESULTS}

Growth of cocci in glycerol and their lipid content

Ten serial subcultures of the Oxford staphylococcus in the culture medium containing $3 \%$ glycerol resulted in a total lipid content of $18 \cdot 8 \pm 0 \cdot 8$; the lipid content of cocci grown under similar circumstances but without glycerol was $6.5 \% \pm 0.4$, in good agreement with the findings of Hugo \& Stretton (I966a, b). Growth curves showed that the presence of glycerol had no significant effect on the log phase or the mean generation time of this organism but the final yield of organisms was higher with glycerol. Because fattened cocci rapidly revert to their normal lipid content after one subculture in the absence of glycerol, all experiments with fattened cocci involving growth were done in the presence of glycerol, $3 \%$ (Fig. I).

\begin{tabular}{|c|c|c|}
\hline \multirow[b]{2}{*}{ Phenol } & \multicolumn{2}{|c|}{$\begin{array}{c}\text { Control cocci } \\
\text { m.i.c. }(\mu \mathrm{g} . / \mathrm{ml} .)\end{array}$} \\
\hline & 2200 & 2200 \\
\hline Cresol & 1300 & 1300 \\
\hline Ethylphenol & 640 & 640 \\
\hline Propylphenol & 390 & 390 \\
\hline$n$-Butylphenol & 85 & 90 \\
\hline$n$-Amylphenol & 38 & 44 \\
\hline$n$-Hexylphenol & 42 & 52 \\
\hline sec.-Butylphenol & 140 & 150 \\
\hline tert.-Amylphenol & 55 & IIO \\
\hline
\end{tabular}

Minimum inhibitory concentrations of phenols

These are presented in Table I. The final inoculum was $10^{6} \mathrm{cocci} / \mathrm{ml}$. As the tubes inoculated with fattened cocci must contain $3 \%$ glycerol and in view of the findings of Cooper (I948) that glycerol in concentrations of $30-40 \%$ depresses the antibacterial 
effects of phenols to the extent of $20-40 \%$, experiments were made on the effect of $3 \%$ glycerol on the minimum inhibitory concentration (m.i.c.) values of the phenols used. At this concentration, glycerol had no detectable effect.

\section{Uptake of phenols by normal and fattened cocci}

Preliminary experiments showed that equilibrium between cocci and the phenol was rapidly attained and was virtually complete in $5 \mathrm{~min}$. The data obtained is shown in Table 2, where it can be seen that the fattened cocci took up slightly less of the phenols tested than did the controls.

Table 2. The uptake of phenols by fattened and unfattened (normal) cocci of Staphylococcus aureus (OXFORD)

\begin{tabular}{lcc} 
Phenol & \multicolumn{2}{c}{ Uptake of phenol, $\mu \mathrm{g} / \mathrm{mg}$ dry wt. cells } \\
Propyl & $42 \cdot 9$ & $46 \cdot 4$ \\
Fattened cells & $27 \cdot 3$ \\
$n$-Butyl & $22 \cdot 2$ & $49 \cdot 9$ \\
$n$-Amyl & $34 \cdot 8$ & $96 \cdot 3$ \\
sec.-Butyl & $84 \cdot 8$ & $50 \cdot 8$ \\
tert.-Amyl & $4 \mathbf{I} \cdot 8$ &
\end{tabular}

Table 3. Staphylococcus aureus (OXFORD). Increase in electrophoretic mobilities as compared with mobilities in buffer of control cocci $(a)$ and fattened cocci $(b)$ in the presence of various concentrations of nine p-alkyl phenols in phosphate buffer ( $\mathrm{pH}_{7} \mathrm{H}^{\text {, }}$ $I=0.0 I$ )

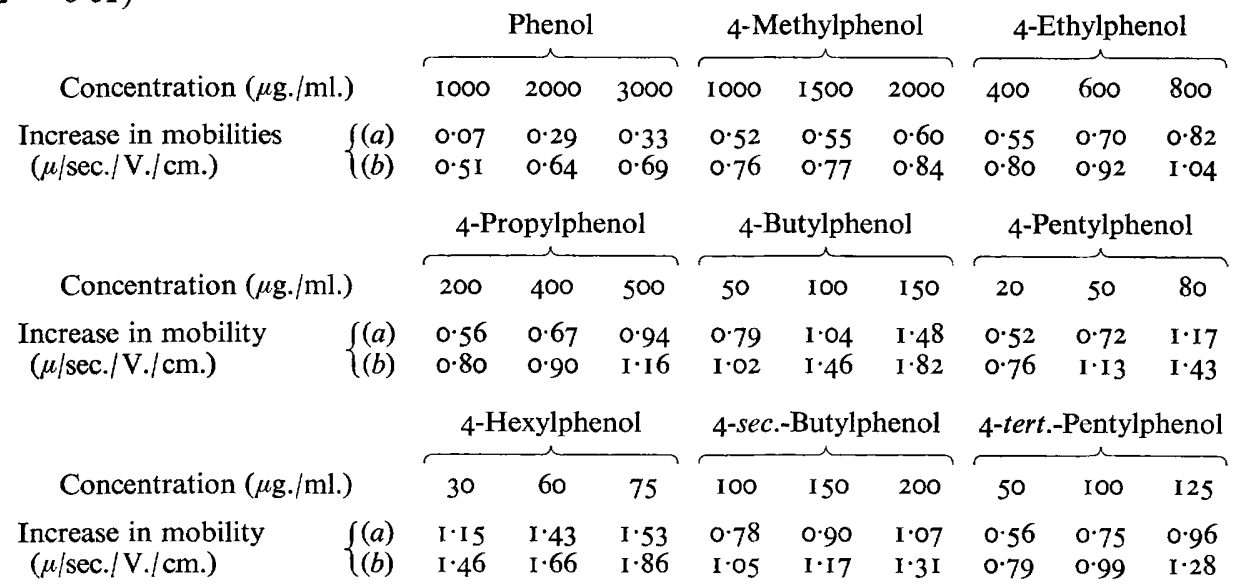

\section{Electrophoretic mobilities}

Mobilities in the presence of sodium dodecylsulphate $(S D S)$. Data obtained in the presence and absence of SDS $\left(10^{-6}, 1^{-5}, 10^{-4} \mathrm{M}\right.$ ) gave figures of a very similar order to that obtained by Hugo \& Stretton (1966a) for the Oxford staphylococcus and confirmed the build-up of surface lipid in the presence of glycerol and its rapid depletion after one subculture in its absence (Fig. I).

Mobilities of fattened and unfattened cocci in the absence of added agent. The 
absolute mobility, $\mu / \mathrm{sec} . / \mathrm{V} . / \mathrm{cm}$. measured on the same day of fattened cocci was 2.002 and of control cells, $2 \cdot 239$, a difference of $10.2 \%$.

Mobilities of fattened and unfattened cells in the presence of phenols. Mobilities were measured at three concentrations of each phenol. The data are presented in Table 3, where it can be seen that whereas the phenols in general increase the negative mobility of the cocci the increase was greater with fattened cocci. The effect of increasing chain length on the mobility differences is shown in Fig. 2. Similar figures were obtained at different initial concentrations of the phenol.

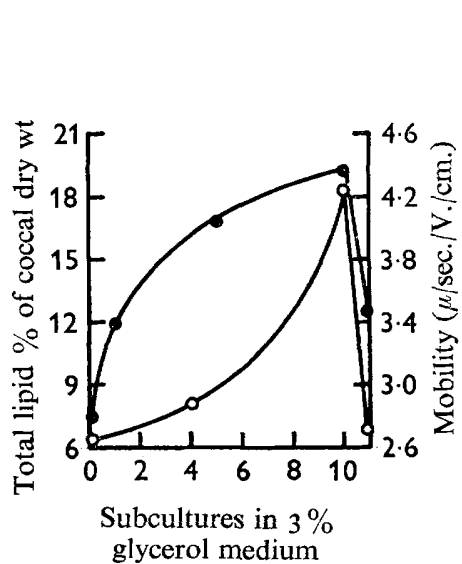

Fig. 1

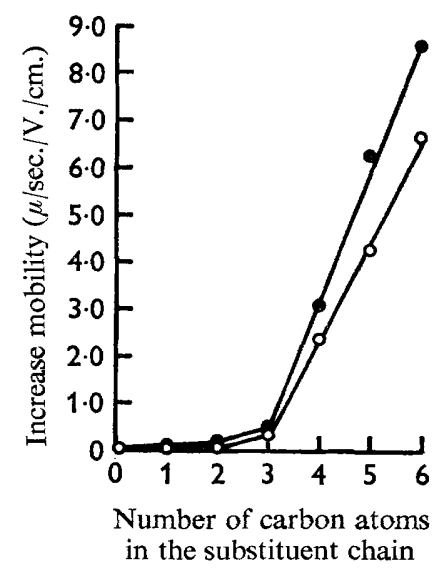

Fig. 2

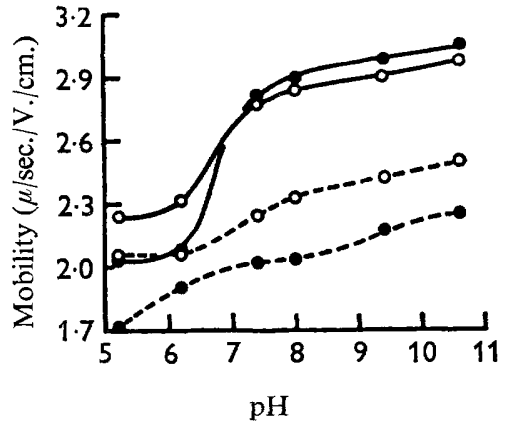

Fig. 3

Fig. I. The build-up of cellular lipid in Staphylococcus aureus (OXFORD) on ro successive subcultures in nutrient broth containing $3 \%$ glycerol and its depletion after one subculture in the absence of glycerol. Total lipid obtained by extraction, $-\mathrm{O}-\mathrm{O}-$; electrophoretic mobility in the presence of $10^{-4} \mathrm{M}-\mathrm{SDS}$,

Fig. 2. Effect of chain length (number of carbon atoms in the 4-alkyl phenol substituent) on the electrophoretic mobility of Staphylococcus aureus (OXFORD) cocci. Fattened cocci, control cocci, $\mathrm{O}-\mathrm{O}$.

Fig. 3. The effect of $\mathrm{pH}$ value on the electrophoretic mobilities of Staphylococcus aureus (OXFORD) cocci in the presence and absence of 4 -ethylphenol $(400 \mu \mathrm{g} . / \mathrm{ml}$.). Control cocci

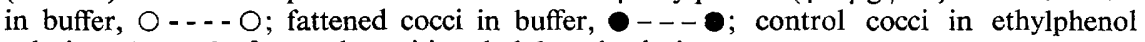
solution, $\mathrm{O}-\mathrm{O}$; fattened cocci in ethylphenol solution,

Effect of $\mathrm{pH}$ on the mobilities of cocci in the presence of phenols. For the range $\mathrm{pH}$ 5-8 phosphate buffer was used and for $\mathrm{pH}$ 8-10.6 carbonate + bicarbonate buffer. Phenol solution, buffer solution and coccal suspensions were mixed so that the final ionic strength of the system was $0 \cdot 0 \mathrm{I}$, and the coccal density equiv. $0.1 \mathrm{mg}$. dry wt $/ \mathrm{ml}$. Similar patterns were found for each of the phenols. The data for $p$-ethylphenol are shown in Fig. 3. This experiment indicated the necessity for controlling the $\mathrm{pH}$ value of the system during electrophoretic studies, for small changes in $\mathrm{pH}$ value over the range $\mathrm{pH} 6-8$ result in marked changes in mobilities.

\section{Phenol-induced leakage of cellular constituents from fattened and unfattened cocci}

When the effect of time on leakage of $260 \mathrm{~m} \mu$ absorbing material and inorganic phosphate was examined, it was found that a rapid initial leakage of both constituents occurred within $2.5 \mathrm{~min}$. In the case of the lower members of the phenol series (up to the propyl compound) it was complete in $30 \mathrm{~min}$, in the remainder it slowly increased 
up to $\mathrm{I} 80 \mathrm{~min}$. When the data for fattened and unfattened cocci are compared it can be seen that there was a rather greater release of these materials from the unfattened cocci. This is illustrated in Table 4, where the leakage of the two cytoplasmic constituents after $15 \mathrm{~min}$. contact with the phenols is presented.

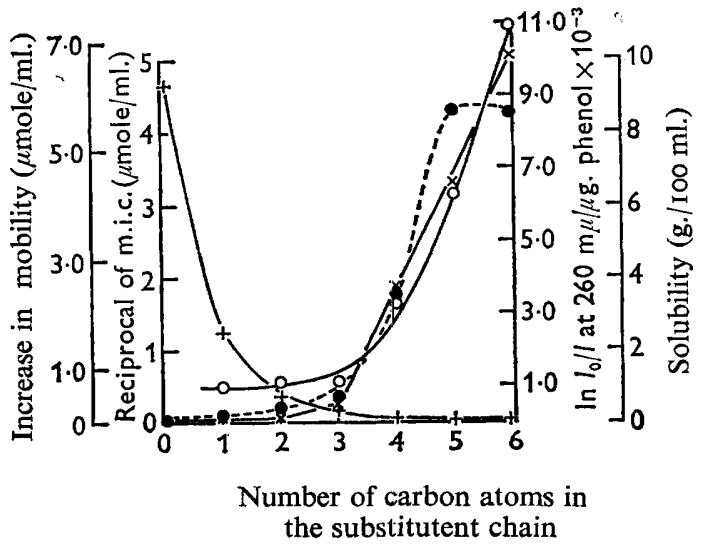

Fig. 4

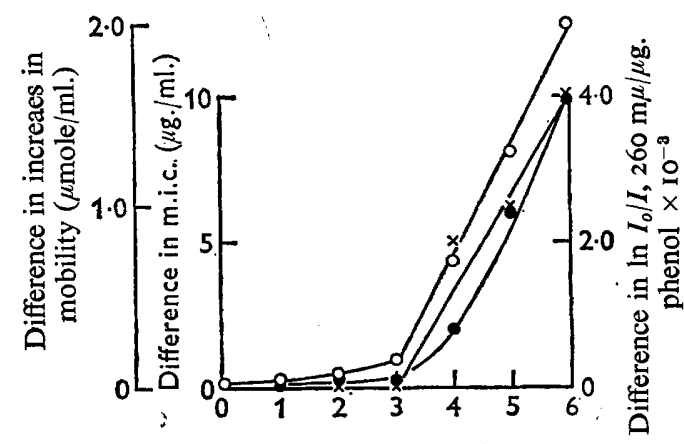

Number of carbon atoms in the substituent chain

Fig. 5

Fig. 4. Staphylococcus aureus (OXFORD). Effect of chain length (number of carbon atoms) in 4-alkyl substituent on: electrophoretic mobility, $\times-\times ; \mathrm{m}$.i.c. plotted reciprocally, -..- - leakage of $260 \mathrm{~m} \mu$ absorbing material, $\mathrm{O}-\mathrm{O}$; water solubility, +---+

Fig. 5. Staphylococcus aureus (OXFORD). Effect of chain length on the difference in observed effect as between control and fattened cocci as measured by: m.i.c. plotted reciprocally, $\times-\times$; electrophoretic mobility, $\mathrm{O}-\mathrm{O}$; leakage of $260 \mathrm{~m} \mu$ absorbing material,

Table 4. Staphylococcus aureus OXFORD. The release of inorganic phosphate (Pi) and 260 mu absorbing material from normal and fattened cocci after treatment for 15 min. with phenols at the concentrations stated

\begin{tabular}{|c|c|c|c|c|c|}
\hline & \multirow{2}{*}{$\begin{array}{l}\text { Concn. } \\
\text { phenol } \\
(\mu \mathrm{g} . / \mathrm{ml} .)\end{array}$} & \multicolumn{2}{|c|}{$\begin{array}{c}\mu \mathrm{g} \mathrm{Pi} / \mathrm{mg}, \text { dry wt. } \\
\text { cocci }\end{array}$} & \multicolumn{2}{|c|}{$\begin{array}{l}\ln I^{\circ} / I(260 \mathrm{~m} \mu) / \mathrm{mg} . \\
\text { dry wt. cocci }\end{array}$} \\
\hline & & Control & Fattened & Control & Fattened \\
\hline Phenol & 500 & 0.44 & 0.41 & - & - \\
\hline 4-Methylphenol & 250 & 0.32 & $0 \cdot 18$ & 0.24 & 0.13 \\
\hline 4-Ethylphenol & 120 & 0.33 & $0 \cdot 28$ & 0.13 & 0.11 \\
\hline 4-Propylphenol & 200 & $0 \cdot 28$ & $0 \cdot 22$ & 0.21 & 0.20 \\
\hline 4-Butylphenol & 100 & 0.53 & $0 \cdot 36$ & $0 \cdot 33$ & 0.25 \\
\hline 4-Pentylphenol & 80 & $2 \cdot 78$ & $2 \cdot 07$ & 0.50 & 0.30 \\
\hline 4-Hexylphenol & 60 & $3 \cdot 33$ & 3.07 & 0.66 & 0.43 \\
\hline 4-sec.-Butylphenol & 200 & 0.63 & 0.60 & 0.45 & $0.4 \mathrm{I}$ \\
\hline 4-tert.-Pentylphenol & 100 & 0.80 & 0.60 & 0.40 & 0.27 \\
\hline
\end{tabular}

\section{Electron micrographs}

Thin sections of the Oxford staphylococcus grown for Io generations in the presence of glycerol showed a distinct thickening of the extra-cytoplasmic layers (Plate I). The thickening appeared to be confined to the walls and was especially pronounced in the septum separating the dividing cocci where presumably active cell-wall synthesis was occurring. 


\section{General}

The inter-relationship of the several criteria and properties used in this work to evaluate coccal interaction are convincingly seen when the results are plotted on one graph as a function of the number of carbon atoms in the 4-primary alkyl substituent. In the first such plot (Fig. 4) the general effect of increasing the number of carbon atoms on the antibacterial and auxiliary activities and properties of phenols upon normal cocci is shown. It is clear that the side chain effect makes itself felt after the $\mathrm{C}_{3}$ (propyl) phenol.

The influence of cellular lipid on the m.i.c., mobility and cytoplasmic integrity as it changes with chain length of the phenols was shown by plotting differences in response at each experimental point as between normal and fattened cocci against alkyl chain length (Fig. 5). Once again the differences become marked after the $-\mathrm{C}_{3}$ compound, suggesting that lipid begins to exert its protective effect when the phenol tends to become more lipid soluble.

\section{DISCUSSION}

It is apparent from evidence from various sources that variation in the level of cellular lipid may be one of the factors involved in bacterial resistance (Chaplin, I952; Church, Halvorson \& Ramsey, 1956; Lowick \& James, 1957; Vaczi \& Farkas, 1961; Ivanov, Markov, Golowinsky \& Charisanova, I964; Truby \& Bennett, 196I).

The use of a homologous series of phenols, such as the 4-normal alkyl phenols, a family of compounds whose properties change in a fairly regular way, with regard to water solubility and distribution coefficient between an aqueous and oily phase, might prove to be an ideal tool to test systematically the effect, if any, of cellular lipid upon resistance.

In considering the data presented in this paper it is reasonable to suppose that the phenols will distribute themselves between the lipid and aqueous components in the cell, in accordance with the normal partition laws, and in the case of fattened cells presumably these phenols will be partially distributed in the deposited lipid.

As the length of the normal alkyl side chain at position 4 increases, not only does the solubility in water decrease and the solubility in lipid increase, but the molecule tends to become polar and consequently surface active. This in turn means that it tends to orientate at an oil/water interface if such an interface is available. In fact changes in response to the phenols as between fattened and normal cells first show themselves distinctly with $n$-butylphenol. In the case of the fattened cell it is likely that, as lipid solubility increases, phenol is immobilized with the alkyl side chain immersed in the cell lipid and the phenolic hydroxy group projecting into the aqueous environment and it could well be that many drug molecules are thus trapped and sensitive areas in the cytoplasmic membrane protected.

This hypothesis receives support from the experimental data obtained. Thus, the smaller amount of material which leaks from fattened as against unfattened cells, which begins to be significant after the butyl compound, is compatible with the hypothesis that the membrane or sensitive areas in it are in some way protected. This, in turn, would explain why, when ability to reproduce (the m.i.c. value) is being measured, the fattened cells are less susceptible to the same dose of drug (above the $\mathrm{C}_{4}$ compound) than are the control cells, for several groups of workers have equated 
one toxic manifestation of non-specific antibacterial drugs with their ability to impair the integrity of the cytoplasmic membrane (Gale \& Taylor, 1947; Salton, I95I ; Beckett, Patki \& Robinson, 1959; Hugo \& Longworth, 1964).

The phenols at equivalent concentration cause an apparent increase in the mobility of the fattened cells as compared with the control cells which is here first noticeable with the $\mathrm{C}_{2}$ compound but again shows a marked difference after the $\mathrm{C}_{4}$. With the $\mathrm{C}_{4}$ compound and thereafter, more molecules are held at the cell surface with the phenolic group projecting into the aqueous fluid in which the cells are suspended. There will be a tendency for these to have a slightly greater negative charge at the surface hence the increased velocity towards the positive electrode for the same applied potential; indeed the phenols here are playing a similar role to that of SDS used as a detector of surface lipid, although of course their degree of ionization is much less.

It can be seen from Fig. 2 that differences between mobilities for fattened and control cells begin to show themselves at the $\mathrm{C}_{2}$ compound; electrophoresis is probably the most sensitive of the methods used in this work to detect drug/cell interaction. It is possible that small differences in response to all the phenols occur, but are only really apparent when they assume an order of magnitude detectable by the experimental method being used. It could well be that m.i.c. measurements, measurements of leakage of metabolites and drug uptake determinations are not of sufficient sensitivity to demonstrate any differences with lower alkyl phenols.

Finally the hypothesis of drug trapping will explain why fattened cells appear to take up less drug than do control cells, a finding which may appear at first sight to contradict the other data obtained. For the experiments used to determine drug uptake cannot distinguish between surface adsorption and general absorption; with the lipid present in the cell, fewer drug molecules penetrate into the cell and the surface becomes saturated, whereas with a normal cell many of the drug molecules taken up will pass into the interior of the cell as well as being held near the surface.

We thank Dr A. R. Hamilton and Unilever Research Laboratories, Colworth House, Bedford, for preparing the electron micrographs of Plate $\mathrm{I}$.

\section{REFERENCES}

Beckett, A. H., PatKi, S. J. \& Robinson, A. (1959). The interaction of phenolic compounds with bacteria. I. Hexylresorcinol and Escherichia coli. J. Pharm. Pharmac. II, 360.

Chaplin, C. E. (1952). Bacterial resistance to quaternary ammonium disinfectants. J. Bact. 63, 453 .

Church, B. D., Halvorson, H. \& Ramsey, D. S. (1956). Population heterogeneity in the resistance of aerobic spores to ethylene oxide. J. Bact. 72, 242.

COOPER, E. A. (1948). Influence of ethylene glycol and glycerol on the germicidal power of aliphatic and aromatic compounds. J. Soc. chem. Ind., Lond. 67, 69.

Fiske, C. H. \& SubBaRow, Y. (I925). The colorimetric determination of phosphorus. J. biol. Chem. 66, 375 .

Gale, E. F. \& TAYLOR, E. S. (1947). The action of tyrocidin and some detergent substances in releasing amino acids from the internal environment of Streptococcus faecalis. J. gen. Microbiol. r, 77 .

Hamilton, W. A. \& STUBBS, J. M. (1967). Comparison of the germination and outgrowth of spores of Bacillus cereus and Bacillus polymyxa. J. gen. Microbiol. 47, I21.

Hugo, W. B. \& Frankind, I. (1966). The influence of cellular lipid on the resistance of microorganisms to antibacterial agents. Abstr. int. Congr. Microbiol. 9, 2 I. 

Journal of General Microbiology, Vol. 52, No. 3

Plate I

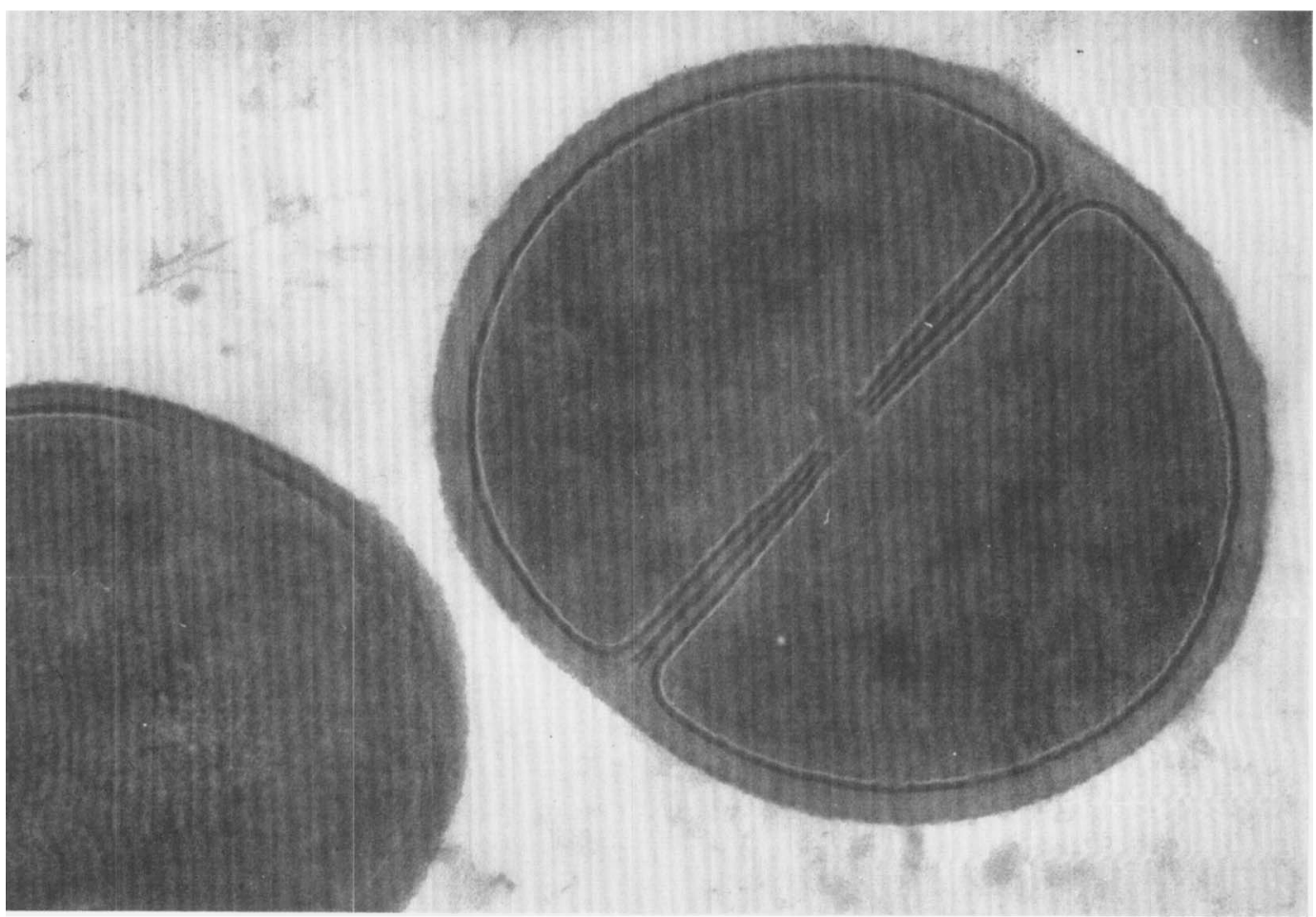

Fig. I

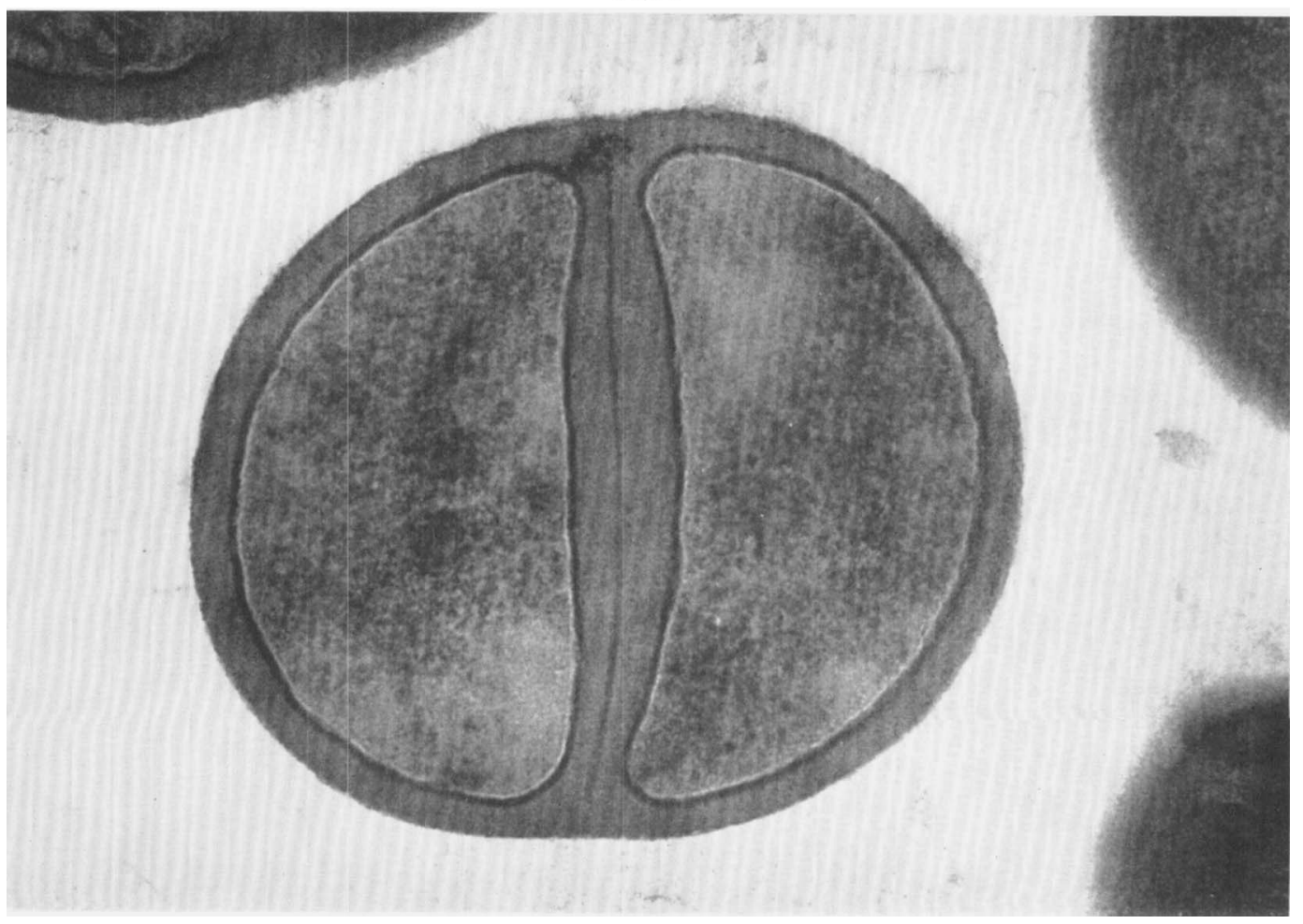

Fig. 2 
Hugo, W. B. \& Longworth, A. R. (I964). Some aspects of the mode of action of chlorhexidine. J. Pharm. Pharmac. 16, 655.

Hugo, W. B. \& Stretton, R. G. (1966a). The role of cellular lipid in the resistance in Gram-positive bacteria to penicillins. J. gen. Microbiol. 42, 133 .

Hugo, W. B. \& Stretton, R. G. (1966 b). Effect of cellular lipid on the sensitivity of some Grampositive bacteria to penicillins. Nature, Lond. 209, 940.

Ivanov, V. W, Markov, K. I., Golowinsky, E. \& Charisanova, T. (I964). Die bedeutung der Oberfläschen-lipide. Z. Naturf. r9 $b, 604$.

LowICK, J. H. B. \& JAMES, A. M. (I957). Electrokinetic properties of Aerobacter aerogenes. A comparison of the properties of normal and crystal violet trained cells. Biochem. J. 65, $43 \mathrm{I}$.

Lykken, L., Treseder, R. S. \& ZAHN, V. (1946). Colorimetric determination of phenols. Application to petroleum and allied products. Ind. Engng Chem. analyt. Edn r8, 103.

Salton, M. R. J. (I95I). The adsorption of cetyltrimethylammonium bromide by bacteria, its action in releasing cellular constituents and its bactericidal effects. J. gen. Microbiol. 5, 39I.

Truby, C. P. \& Bennetr, E. O. (I96I). Role of lipid in the protection of Staphylococcus aureus against trichlorophenol in mixed culture. Appl. Microbiol. 14, 769.

VACZI, F. \& FARKAS, L. (I96I). Association between lipid metabolism and antibiotic sensitivity. I. The lipid composition of antibiotic sensitive and resistant Staphylococcus aureus strains. Acta microbiol. hung. 8, 205

\section{EXPLANATION OF PLATE}

Fig. I. Thin section of Staphylococcus aureus (OXFORD) grown in nutrient broth. $\times 30,000$.

Fig. 2. Thin section of Staphylococcus aureus (OXFORD) after growth for ten generations in nutrient broth containing $3 \%$ glycerol. $\times 30,000$. 